\title{
Pandemia de Covid-19: o comportamento de cães e a relação com seus tutores
}

\section{durante o isolamento social}

\author{
Covid pandemic-19: dog behavior and the relationship with their guardians during social isolation \\ Pandemia de Covid-19: comportamiento del perro y la relación con sus tutores durante el aislamiento \\ social
}

Fernanda Dagmar Martins Krug

ORCID: https://orcid.org/0000-0001-9123-9399 Instituto Federal do Norte de Minas Gerais, Brasil Universidade Federal de Pelotas, Brasil Universidade de Cruz Alta, Brasil E-mail: fernandadmkrug@gmail.com

Clederson Idenio Schmitt

ORCID: https://orcid.org/0000-0001-7948-9627 Universidade Federal de Pelotas, Brasil Instituto Federal Sul Riograndense, Brasil E-mail: schmittproducoes@gmail.com Sabrina de Oliveira Capella ORCID: https://orcid.org/0000-0001-8252-2096 Universidade Federal de Pelotas, Brasil E-mail: capellas.oliveira@gmail.com

Mariana Cristina Hoeppner Rondelli ORCID: https://orcid.org/0000-0001-5385-8228 Universidade Estadual Paulista, Brasil Universidade Federal de Pelotas, Brasil E-mail: marianarondelli@gmail.com

Marcia de Oliveira Nobre

ORCID: https://orcid.org/0000-0003-3284-9167 Universidade Federal de Pelotas, Brasil E-mail: marciaonobre@gmail.com

\begin{abstract}
Resumo
No ano de 2020 foi declarado pela Organização Mundial de Saúde um surto que se espalhou rapidamente por todos os continentes, o Covid-19. No Brasil e demais países da América Latina foi decretada uma série de regras para desacelerar o contágio do vírus. Uma delas foi o isolamento social, que alterou a rotina de várias pessoas e também dos animais de estimação. Por isso, o objetivo do nosso estudo foi identificar alterações comportamentais em cães e investigar a relação com seus tutores durante o isolamento social no período da pandemia de Covid-19. Um questionário para identificar possíveis alterações comportamentais em cães foi disponibilizado em redes sociais e enviado por e-mail. 1532 respostas foram registradas, de tutores que eram, a maioria, jovens/adultos, na faixa etária dos 24 aos 35 anos, estavam fazendo isolamento social, porém saiam para realizar tarefas essenciais e se identificaram com o gênero feminino. Nossos resultados demonstraram que, nesse período de pandemia, houve maior convívio dos tutores com seus cães. Além disso, os cães não demonstraram sinais de estresse, ansiedade e agressividade. Pelo contrário, mostraram-se mais apegados, formando um vínculo de hiperapego com seus tutores. Conclui-se que, nesse período, não foram identificados sinais comportamentais de estresse e agressividade nos cães. Foram constatados sinais de hiperapego, como chorosos e tristes quando separados dos tutores e mais dependentes. Com relação aos tutores, a maioria eram jovens/adultos, estavam fazendo isolamento social, porém saiam para realizar tarefas essenciais e se identificaram com o gênero feminino.

Palavras-chave: Alterações comportamentais; Hiperapego; Questionário.
\end{abstract}

\begin{abstract}
In the year 2020 an outbreak that spread rapidly to all continents, Covid-19, was declared by the World Health Organization. In Brazil and other countries in Latin America, a series of rules were enacted to slow down the spread of the virus. One of them was social isolation, which changed the routine of many people and also of pets. Therefore, the aim of our study was to identify behavioral changes in dogs and investigate the relationship with their guardians during social isolation during the Covid-19 pandemic period. A questionnaire to identify possible behavioral changes in dogs was made available on social networks and sent by email. 1532 responses were recorded, from tutors who were mostly young/adults, aged between 24 and 35 years old, who were socially isolated, but went out to perform essential tasks and
\end{abstract}


identified themselves with the female gender. Our results showed that, during this period of pandemic, there was greater interaction between tutors and their dogs. Furthermore, the dogs showed no signs of stress, anxiety and aggression. On the contrary, they were more attached, forming a hyperattachment bond with their tutors. It is concluded that, during this period, behavioral signs of stress and aggression in dogs were not identified. Signs of hyperattachment were found, such as crying and sad when separated from the guardians and more dependent. Regarding the tutors, most were young/adults, were socially isolated, but went out to perform essential tasks and identified with the female gender.

Keywords: Behavioral changes; Hyperattachment; Quiz.

\section{Resumen}

En el año 2020, la Organización Mundial de la Salud declaró un brote que se extendió rápidamente a todos los continentes, el Covid-19. En Brasil y otros países de América Latina, se promulgaron una serie de reglas para frenar la propagación del virus. Uno de ellos fue el aislamiento social, que cambió la rutina de muchas personas y también de las mascotas. Por lo tanto, el objetivo de nuestro estudio fue identificar cambios de comportamiento en perros e investigar la relación con sus tutores durante el aislamiento social durante el período de la pandemia de Covid-19. Un cuestionario para identificar posibles cambios de comportamiento en perros se puso a disposición en las redes sociales y se envió por correo electrónico. Se registraron 1532 respuestas, de tutores en su mayoría jóvenes / adultos, con edades entre 24 y 35 años, que se encontraban socialmente aislados, pero que salían a realizar tareas esenciales y se identificaban con el género femenino. Nuestros resultados mostraron que, durante este período de pandemia, hubo una mayor interacción entre los tutores y sus perros. Además, los perros no mostraron signos de estrés, ansiedad y agresión. Por el contrario, estaban más apegados, formando un vínculo de hiperenlace con sus tutores. Se concluye que, durante este período, no se identificaron signos conductuales de estrés y agresión en los perros. Se encontraron signos de hiperactividad, como llanto y tristeza cuando se separa de los guardianes y se vuelve más dependiente. En cuanto a los tutores, la mayoría eran jóvenes /adultos, se encontraban aislados socialmente, pero salían a realizar tareas esenciales y se identificaban con el género femenino.

Palabras clave: Cambios de comportamiento; Hiperactividad; Examen.

\section{Introdução}

Em 2019, foi relatado na China, mais especificamente na cidade de Wuhan, o primeiro caso da Síndrome Respiratória Aguda Grave (SARS), associado a uma nova cepa de coronavírus (Lopes et al., 2020). Foi então declarado em 2020, pela Organização Mundial de Saúde (OMS), um surto de interesse mundial que se espalhou rapidamente por vários continentes, nomeado de "novo coronavírus" Covid-19 (Rothan \& Byrareddy, 2020). Muitos estudos foram realizados para comprovar a origem desse vírus e uma das hipóteses é que inicialmente o vírus foi hospedado por morcegos e transmitido para os seres humanos através de pangolins, que são mamíferos que vivem nas zonas tropicais da Ásia e África (Bogoch et al., 2020; Lopes et al., 2020; Wan et al., 2020).

Com isso, surgiram muitas dúvidas se os animais domésticos poderiam transmitir a doença aos humanos, já que o coronavírus está presente em várias doenças em humanos, animais domésticos e selvagens (Lu et al., 2020). Porém, algumas pesquisas não confirmaram essa hipótese, sendo uma delas uma pesquisa realizada pela AFCD (Agriculture, Fisheries and Conservation Department) de Hong Kong, que realizou testes em 17 cães e oito gatos em residências com pessoas confirmadas com Covid-19. Destes dois cães e um gato apresentaram resultados positivos (Mcmichael \& Clark, 2020; World HEALTH Organization, 2020; Wan et al., 2020). Assim como em outros estudos, esses animais não apresentaram sinais clínicos da doença, indicando que não há evidências de que os animais domésticos disseminem o novo coronavírus para outros animais/humanos (Lopes et al., 2020).

No Brasil, Argentina, Chile e em outros países da América do Sul surgiram, com a Pandemia, medidas de controle e disseminação da doença pelas autoridades sanitárias, dentre elas foram declarados, a quarentena e o isolamento social em março de 2020 (Rothan \& Byrareddy, 2020), momento em que muitas pessoas tiveram que adaptar-se a nova forma de trabalho, o Home Office, além de alterar a rotina de seus lares, como a convivência com outros membros da família, entre eles, os animais domésticos (Devotto et al., 2020). Devido ao isolamento social, muitos tutores começaram a passar mais tempo com seus Pets, tiveram que reduzir os passeios e repensar formas de adaptar suas residências para criar enriquecimento ambiental e driblar as alterações de comportamento que esse "novo normal" pode desencadear nos animais. 
Assim como os tutores consideram os cães como parte da família, os cães assimilam que os tutores também fazem parte da sua matilha. Essa relação de dependência emocional pode favorecer o aparecimento de comportamentos indesejados e situações bem pontuais. Uma vez que os cães, assim como nós, possuem necessidades emocionais, e quando os mantemos com restrições de exercerem os comportamentos normais da espécie, surgem as desordens emocionais (Machado \& S'antaanna, 2017). As alterações comportamentais surgem porque os animais podem passar mais tempo em um mesmo ambiente, e consequentemente não poderão exercer seus comportamentos naturais, gerando sinais de estresse e ansiedade. Os sinais comportamentais mais comuns são: vocalização excessiva, automutilação, eliminação de excretas em locais inapropriados, prostração e até mesmo agressividade (ASSIS et al., 2020).

Visando esses fatores e a importância da realização de um estudo inédito, para identificar possíveis alterações comportamentais causadas pelo isolamento social durante o período de pandemia de Covid- 19, no Brasil e em outros países, o objetivo do nosso estudo foi identificar alterações comportamentais em cães e investigar a relação com seus tutores durante o isolamento social no período da pandemia de Covid-19.

\section{Metodologia}

Foi elaborado um questionário observacional, adaptado de Landsberg (2005), Overall (2013) e Krug et al. (2019), para pesquisar alterações comportamentais de cães durante o período de isolamento social, dividido em duas seções, com questões dissertativas e objetivas, enviado por e-mail e disponibilizado por meio de mídias sociais, pelo link: , disponível por um período de três meses, de junho a agosto de 2020. Para a realização do estudo, poderiam acessar o questionário tutores de cães de qualquer idade, os mesmos não foram identificados e poderiam ser residentes no Brasil e de outros países, para tanto o questionário foi desenvolvido em três idiomas: português, inglês e espanhol.

A primeira seção era composta por perguntas relacionadas ao tutor como: País de origem, tipo de moradia, o número de pessoas residentes na moradia, faixa etária, gênero, se estava em isolamento social, se na cidade houve casos de COVID-19 e se a cidade decretou lockdown. Na segunda seção, as questões eram relacionadas ao cão: idade, sexo, estado reprodutivo e porte. Na terceira seção foram realizadas perguntas relacionadas ao comportamento do cão antes e durante a pandemia (Tabela 1). Os resultados do questionário foram cruzados por meio de testes de qui-quadrado em software estatístico Statistic 25. Considerou-se um nível mínimo de confiança de 95\% em todas as análises estatísticas. 
Tabela 1 - Perguntas sobre o comportamento dos cães antes e durante a Pandemia de COVID-19 respondidas por meio de questionário online por seus tutores.

\begin{tabular}{cc}
\hline \multicolumn{2}{c}{ Comportamento dos cães antes da Pandemia } \\
\hline Parâmetros & Alternativas \\
Como era o comportamento do seu cão antes da Pandemia? & Calmo; Medroso; Ansioso; Agressivo. \\
Passeava com seu cão? Com qual frequência? & $\begin{array}{c}\text { Uma vez ao dia; Duas vezes ao dia; Três } \\
\text { vezes ao dia; Semanalmente; Não passeava. }\end{array}$ \\
\hline Comportamento durante a Pandemia
\end{tabular}

\section{Comportamento durante a Pandemia}

\section{Parâmetros}

Você tem passado mais tempo junto com seu cão?

Atualmente passeia com seu cão? Com qual frequência?

Seu cão está lambendo mais as patas?

Percebeu se ultimamente seu cão está bocejando mais?

Seu cão está lambendo mais os lábios?

Seu cão tenta abocanhar objetos imaginários?

Seu cão está tentando perseguir/morder a própria cauda?

Está apresentando andar estereotipado?

Intensificou o hábito de dar voltinhas ao seu redor?

Está vocalizando mais do que de costume?

Seu cão está mais inquieto/agitado?

Seu animal está se isolando ou tentando esconder-se?

Seu cão fica mais choroso/triste quando separado do tutor?

Demonstra mais interesse em carinhos/ está mais dependente?

Está mais agressivo com pessoas/animais?

Está apresentando comportamentos destrutivos?

Está eliminando excretas em locais inapropriados?
Sim, quase 24 horas por dia; quase 12 horas por dia; quase 6 horas por dia; junto com meu cão;

dizer.
Sim, Sim, Não fico Não sei
Sim, passeio $1 \mathrm{x}$ ao dia;

Sim, passeio $2 \mathrm{x}$ ao dia; Sim, passeio $3 \mathrm{x}$ ao dia ou mais, Não passeio
Sim, com maior frequência;

Sempre teve esse hábito;

Não tem esse hábito

Fonte: Autores.

\section{Resultados e Discussões}


Os resultados demonstraram que nesse período de pandemia em 2020, houve maior convívio dos tutores com seus cães. Além disso, os cães não demonstraram sinais de estresse, ansiedade e agressividade. Pelo contrário, mostraram-se mais apegados, formando um vínculo de hiperapego com seus tutores. A seguir, detalharemos mais os resultados do nosso estudo.

Obtivemos total de 1532 respostas, das quais (1365 - 89\%) eram de tutores brasileiros e (167-11\%) de tutores de outros países, como: Chile, Equador, Colômbia, México, Peru, Argentina, Uruguai, Espanha, Venezuela, Estados Unidos, Irlanda, Portugal, República Dominicana, Inglaterra, África do Sul, Bolívia, Guatemala e Costa Rica. Esses dados refletem numa tendência mundial, onde cada vez mais as famílias têm animais de estimação. No Brasil, segundo o Instituto Pet Brasil que divulgou dados atualizados de um censo realizado em todo território nacional, foram contabilizados 54,2 milhões de cães em nosso País (Abinpet,2014). No Reino Unido, um quarto das famílias possuem pelo menos um cão, na Hungria esse número aumenta em 33\% e nos Estados Unidos aumenta em até 44\% (Assis et al., 2020).

O local de moradia da maioria dos tutores que participaram do estudo era casa com quintal $(1002-65,4 \%)$, onde residiam com três pessoas ou mais (944 - 61,7\%), salienta-se que dependendo do ambiente pode afetar diretamente o bem-estar físico e mental dos cães pela presença ou não de espaço para atividades físicas e de enriquecimento ambiental (Machado \& S’antaanna, 2017).

Os tutores (Tabela 2) eram principalmente jovens/ adultos, da faixa etária dos 20 aos 24 anos (31,3\%) e dos 25 aos 35 anos $(28,1 \%)$, sendo do gênero feminino $(83,7 \%)$. A maioria estava respeitando o isolamento social, porém saía para realizar tarefas essenciais como mercado, farmácia, padaria (77,4\%) (Tabela 3). Acredita-se que isso ocorreu, pois os jovens adultos estão mais "conectados" no mundo digital, principalmente no período de isolamento social, onde a maioria das pessoas estavam estudando e/ou trabalhando em casa. Em relação ao gênero, a maioria dos tutores identificou-se como feminino. Supõe-se, que isso ocorreu porque as mulheres buscam cada vez mais seu lugar nas diversas áreas da sociedade (Grossi et al., 2016) e tendem ser mais participativas e resolverem as questões a sua volta.

Sobre os casos de Covid-19 nas cidades, (1095 - 71,5\%) dos tutores relataram que havia mais de 3.000 casos nas suas cidades, (416-27,2\%) disseram que havia menos de 30 casos e $(21-1,4 \%)$ não havia casos da doença na cidade. Quando consideramos o Lockdown, o confinamento total foi decretado em apenas (508 -33,2\%) das cidades.

Tabela 2 - Faixa etária e gênero dos tutores que responderam o questionário.

\begin{tabular}{cc}
\hline Faixa Etária & $\mathbf{n}(\boldsymbol{\%})$ \\
\hline 15 a 19 anos & $180(11,7)$ \\
20 a 24 anos & $480(31,3)$ \\
25 a 35 anos & $432(28,1)$ \\
36 a 45 anos & $221(14,4)$ \\
46 a 59 anos & $184(12)$ \\
60 anos ou mais & $35(92,2)$ \\
& \\
\hline Gênero & $\mathbf{n}(\%)$ \\
\hline Feminino & $1283(83,7)$ \\
Masculino & $179(11,7)$ \\
IBQTI+ & $70(4,6 \%)$ \\
\hline
\end{tabular}

Fonte: Autores.

Tabela 3 - Demonstração do grau de isolamento social como medida de proteção contra o COVID-19, que se encontravam os tutores participantes desse estudo 


\begin{tabular}{cc}
\hline Isolamento Social & $\mathbf{n}(\boldsymbol{\%})$ \\
\hline Porém saia para realizar tarefas essenciais & $1186(77,4)$ \\
Completamente isolado & $168(11)$ \\
Não fiz isolamento & $178(11,6)$ \\
\hline
\end{tabular}

Fonte: Autores.

Com relação às características dos cães (Tabela 4), grande parte eram idosos, tinham sete anos ou mais. Esse número maior de cães idosos corrobora o aumento da expectativa de vida canina, sendo o resultado de um melhor conhecimento sobre a saúde, qualidade nutricional, controle sanitário e diagnósticos mais eficazes por parte dos médicos veterinários e o cuidado por parte dos tutores (Krug et al., 2019). Sendo que, a maioria dos cães, (873 - 57\%) eram fêmeas, (900 - 58,8\%) eram castrados, (717 - 46,8\%) eram de porte pequeno e $(915$ - 59,7\%) de raça definida. O sexo, estado reprodutivo e idade dos cães podem contribuir para o aparecimento de doenças crônica e outros fatores não biológicos, como ambiente, comportamento, sociais e econômicos podem tem efeitos na saúde canina (Wallis et al., 2018).

Tabela 4. Perfil dos cães, através da faixa etária, porte, sexo, estado reprodutivo e raça.

\begin{tabular}{|c|c|c|c|c|}
\hline Parâmetros & & & & \\
\hline \multirow{2}{*}{ Faixa etária } & $\begin{array}{c}\text { Filhotes (0-1 } \\
\text { ano) }\end{array}$ & $\begin{array}{c}\text { Jovens (2 - } 3 \\
\text { anos }\end{array}$ & $\begin{array}{c}\text { Adultos (4-6 } \\
\text { anos) }\end{array}$ & $\begin{array}{c}\text { Idosos ( } 7 \text { anos ou } \\
\text { mais) }\end{array}$ \\
\hline & $117(7,6)$ & $120(7,8)$ & $556(36,3)$ & $739(48,2)$ \\
\hline \multirow[b]{2}{*}{ Porte } & Pequeno & Médio & Grande & \\
\hline & $717(46,8)$ & $570(37,2)$ & $245(16)$ & \\
\hline \multirow{2}{*}{ Sexo } & Fêmeas & Machos & & \\
\hline & $873(57)$ & $659(43)$ & & \\
\hline \multirow{2}{*}{ Estado Reprodutivo } & Castrados & Não castrados & & \\
\hline & $900(58,8)$ & $632(41,2)$ & & \\
\hline \multirow[t]{2}{*}{ Raça } & Com raça & $\begin{array}{c}\text { Sem raça } \\
\text { definida }\end{array}$ & & \\
\hline & $915(59,7)$ & $617(40,3)$ & & \\
\hline
\end{tabular}

Fonte: Autores.

Os cães, antes da pandemia apresentavam principalmente o comportamento calmo $(993$ - 64,8\%) e ansioso (420 27,5\%), em número menor medo, (92 - 6\%) e agressividade (27-1,7\%). Observou-se que nem todos os animais comportam-se da mesma forma quando enfrentam a mesma situação (Camps et al., 2019), como em um estudo desenvolvido no Japão em que verificaram que $86 \%$ dos cães exibiram pelo menos um problema comportamental (Yamada et al., 2019). Porém, os tutores estimulavam os cães através de brincadeiras, sendo que a grande maioria (1394 - 91\%) tinham o hábito de estimular seus cães e apenas (138 - 9\%) não estimulavam. O estímulo por brincadeiras é uma experiência muito prazerosa para os cães, fortalece o vínculo entre tutor e animal (Arden \& Adams, 2016). Logo, esse comportamento lúdico proporciona bem-estar positivo para o cão (Arden \& Adams, 2016). Quanto aos passeios, (351 - 29,6\%) tutores afirmaram que não passeavam com seu cão, (313 - 
26,4\%) passeavam semanalmente e (261 - 22\%) passeavam pelo menos uma vez ao dia. Essa redução dos passeios esteja ligada ao medo e a insegurança que a pandemia estava ocasionando nos tutores.

Com relação, aos passeios com os cães, quando cruzamos os dados dos tutores durante o isolamento social versus se atualmente passeavam com seus cães, obtivemos os seguintes resultados: (659 - 55,6\%) saíam apenas para tarefas essenciais, não passeavam mais com os seus cães, respeitando as regras estabelecidas pelos órgãos de saúde e (31 - 18,5\%) passeavam apenas uma vez ao dia. Estes dados demonstraram a redução dos passeios entre tutores e os cães, confirmando que ambos passaram a conviver por mais tempo juntos em casa, ou seja, (819 - 69,1\%) permaneciam 24 horas com seus cães.

Nos cães desse estudo, não foram identificados sinais comportamentais significativos de estresse e agressividade (Figura 1). Mesmo com todas as restrições do isolamento social, observou-se que os cães puderam ter experiências emocionais positivas, oportunidade de interagir mais com seus tutores e com o ambiente onde vivem, o que resultou na ausência de manifestação dessas alterações comportamentais. No entanto, é fundamental que os tutores saibam identificar os comportamentos, sejam eles positivos e/ou negativos nos seus cães, para proporcionar saúde e bem-estar aos mesmos (Rehn et al., 2017). No entanto, surge uma preocupação de como será o pós-pandemia, se essa relação vai continuar ou vai diminuir, já que os tutores irão voltar as suas rotinas que eles tinham.

Porém, identificamos que nesse período os cães estavam mais chorosos/tristes quando separados dos seus tutores $(\mathrm{p}=0,015)$ e estavam pedindo mais carinhos e dependentes $(0,004)$. Isso pode demonstrar uma relação de apego, entre cães e tutores, ou seja, uma ligação afetuosa semelhante ao que ocorre numa relação entre pais e filhos. Muitas vezes os cães exibem esse comportamento de apego, demonstrando uma preferência por seus tutores (Csoltova \& Mehinagic, 2020). 
Figura 1. Porcentagem de alterações comportamentais dos cães durante a pandemia.

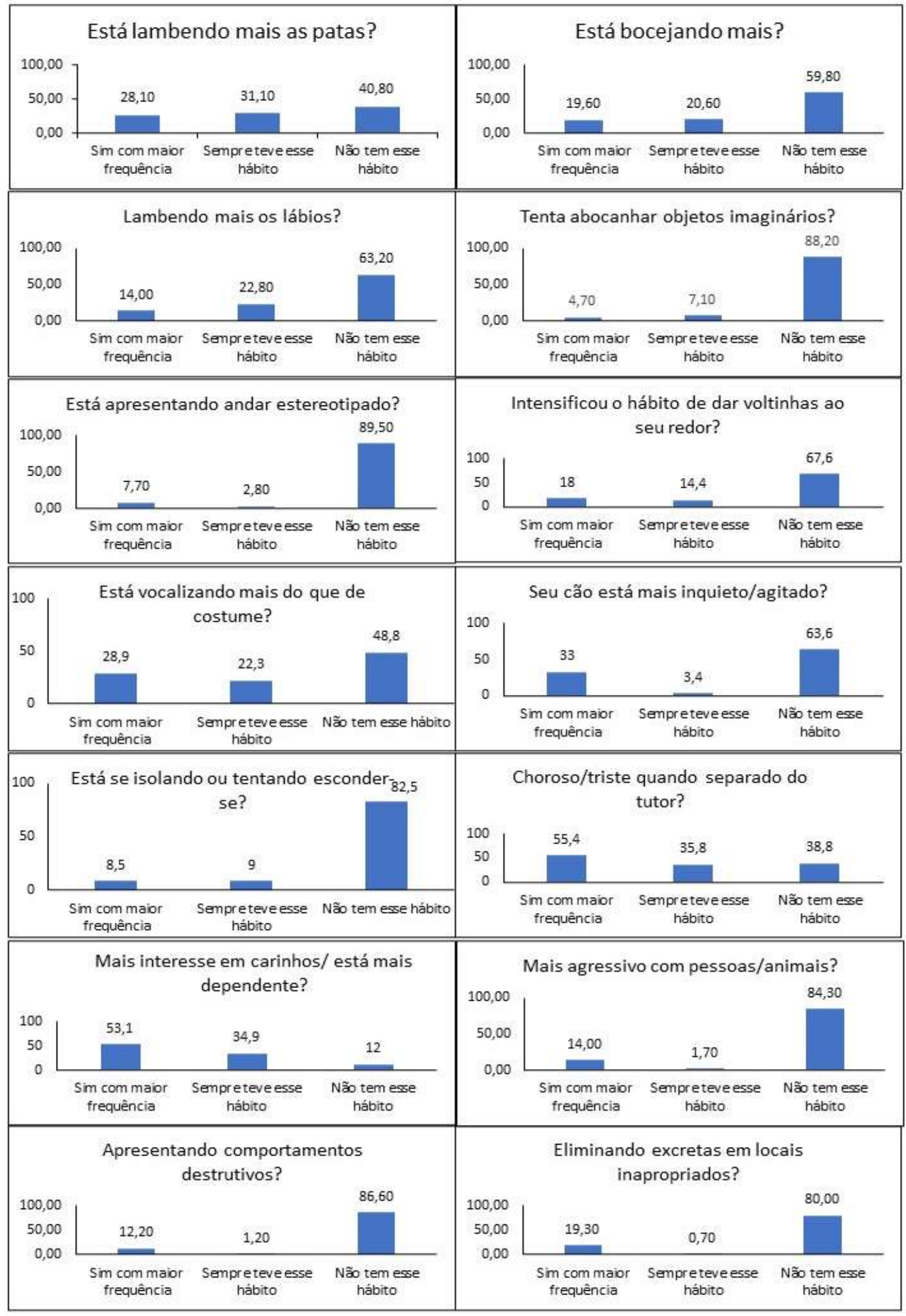

Fonte: Autores.

No entanto, quando esses comportamentos se tornam exacerbados, pode desencadear um comportamento de hiperapego, uma dependência excessiva do tutor que não é saudável para a relação de ambos. Essa relação de hiperapego e o excesso de 
cuidados por partes dos tutores poderão levar os cães ao estresse ou serem indicativos de um início de uma ansiedade de separação (SAS) (Rehn et al., 2017). Por isso, os tutores devem ficar atentos ao comportamento dos cães no período de isolamento social e após, quando retornarem para as suas atividades por completo, para evitar possíveis transtornos.

Ao realizar o cruzamento dos resultados do porte, sexo, estado reprodutivo e raça dos cães, com os sinais comportamentais, obtivemos resultados relevantes. Com relação ao porte, os cães de porte pequeno, (220 - 30,7\%) apresentaram o hábito de lamber mais as patas e (424 - 59,1\%) estavam mais chorosos/tristes. Com relação ao sexo e estado reprodutivo não foi encontrada relação com as alterações comportamentais. Este resultado difere de outras pesquisas, que destacam que cães castrados têm maiores chances de desenvolver alterações comportamentais (Storengen et al., 2014). Dos (521 - 56,9\%) (p=0,000) de cães com raça definida, sempre tiveram esse comportamento de carinho/mais dependentes de seus tutores e (322 - 35,2\%) sempre tiveram o comportamento de lambedura de patas.

\section{Conclusão}

Conclui-se que, nesse período, não foram identificados sinais comportamentais de estresse e agressividade nos cães. Foram constatados sinais de hiperapego, como chorosos e tristes quando separados dos tutores e mais dependentes. Com relação aos tutores, a maioria eram jovens/adultos, estavam fazendo isolamento social, porém saiam para realizar tarefas essenciais e se identificaram com o gênero feminino.

Se faz necessário, novos estudos para o pós-pandemia para identificar como estará o comportamento desses cães, se os sinais de hiperapego irão aumentar ou diminuir, já que seus tutores irão voltar a rotina normal.

\section{Agradecimentos}

A CAPES e CNPq (308152/2019-0) pela concessão de bolsas e apoio financeiro do primeiro autor.

\section{Referências}

Abinpet. Associação Brasileira da Indústria de Produtos para Animais de Estimação (2014). Informações gerais do setor pet. http://abinpet.org.br/infos_gerais/ Arden, R., \& Adams, M. J. (2016). A general intelligence factor in dogs. Intelligence 55, 79-85. https://doi.org/10.1016/j.intell.2016.01.008

Bogoch, A. W., Thomas-Bachli, C., Huber, M. U. G., \& Kraemer, K. K. (2020). Pneumonia of unknown etiology in wuhan, China: potential for international spread via commercial air travel. J Travel Med. 2020 Mar, 27(2): taaa008. https://dx.doi.org/10.1093\%2Fjtm\%2Ftaaa008

Camps, T., Amat, M., \& Manteca, X. (2019). A Review of Medical Conditions and Behavioral Problems in Dogs and Cats. Animals. 9 (12): 1133. https://doi.org/10.3390/ani9121133

Csoltova, E., \& Mehianagic, E. (2020). Where do we stand in the domestic dog (canis familiaris) positive-emotion assessmente: a state of the art review and future directions. Frontiers in Psicohology. v. 11. https://doi.org/10.3389/fpsyg.2020.02131

De Assis, L. S., Matos, R., Pike, T. W., Burmann, O. H. P., \& Mills, D. S. (2020). Developing diagnostic frameworks in veterinary behavioral medicine: disambiguating separation related problems in dogs. Frontiers em veterinary Sciense. v. 6. https://doi.org/10.3389/fvets.2019.00499

Devotto, R., Oliveira, D. S., Ziebell, M., Freitas, C. P. P., \& Vazquez, A. C. S. (2020). Guia de Bem-estar no Trabalho em Tempos de Pandemia para Profissionais em Home Office. UFCSPA.

Grossi, M. G. R., Borja, S. D. B., Lopes, A. M., \& Andalécio, A. M. L. (2016). As mulheres praticando ciência no Brasil. Revista Estudos Feministas. 24(1), 11, https://doi.org/10.1590/1805-9584-2016v24n1p11

Krug, F. D. M., Tillmann, M. T., Pineiro, M. B. C., Capella, S. O., Costa, A. L., Bruhn, F. R. P., \& Nobre, M. O. (2019). Evaluation of cognitive dysfunction syndrome in dogs using an observational questionnaire. Semina Ciências Agrárias (ONLINE), 40, 1. https://doi.org/10.5433/1679-0359.2019v40n5Supl1p2235

Landsberg, G. (2005). Therapeutic agents for the treatment of cognitive dysfunction syndrome in senior dogs. Biol. Psychiatry, 29,471-479, https://doi.org/10.1016/j.pnpbp.2004.12.012

Lopes, O. F. M, Gomes, N. R. S., Freitas, D. R. J., \& Evangelista, L. S. M. (2020). COVID-19 and the domestic animals: are there some evidence relationship between them? Journal of Health \& Biological Scienses. 8(1). Unichristus. http://dx.doi.org/10.12662/2317-3076jhbs.v8i1.3225.p1-6.2020

Lu, R., Zhao, X., Lij., Niu, P., Yang, B., \& Wu, H. (2020). Genomic characterisation and epidemiology of 2019 novel coronavirus: implications for virus origins and receptor binding. The Lancet.395, 565 - 574. https://doi.org/10.1016/s0140-6736(20)30251-8 
Research, Society and Development, v. 10, n. 14, e508101420162, 2021

(CC BY 4.0) | ISSN 2525-3409 | DOI: http://dx.doi.org/10.33448/rsd-v10i14.20162

Machado, D. S., \& Sant’anna, A. (2017). Síndrome de ansiedade por separação em animais de companhia: uma revisão. Revista Brasileira de Zoociências. 8(3), 159-186. https://doi.org/10.34019/2596-3325.2017.v18.24682

Mcmichael, T. M., Clark, S., Pogosjans, S. et al. COVID-19 in a long-term care facility—King County, Washington, https://doi.org/10.15585/mmwr.mm6912e1

Overall, K. (2013). Manual of clinical behavioral medicine for dogs and cats. 832.

Rehn, T., Beetz, A., \& Keeling, L. J. (2017). Links between an Owner's adult attachment style and the support-seeking behavior of their dog. Front. Psychol. https://doi.org/10.3389/fpsyg.2017.02059

Rothan, A. H, \& Byrareddy, S. N. (2020). The epidemiology and pathogenesis of coronavirus disease (COVID-19) outbreak. Journal of Autoimmunity. v.109. https://doi.org/10.1016/j.jaut.2020.102433

Schöberl, I., Wedl, M., Beetz A., \& Kotrschal, K. (2015). Fatores que influenciam os padrões de cortisol em cães durante uma situação estranha Teste. J. Vet. Behav. https://doi.org/10.1016/j.jveb.2015.09.007

Solomon, J., Beetz, A., Schöberl, I., Gee, N., \& Kotrschal, K. (2018). Segurança de fixação em cães de companhia: adaptação da situação estranha de Ainsworth e procedimentos de classificação para cães e seus cuidadores humanos. Attach Hum Dev. Aug, 21(4), 389-417 https://doi.org/10.1080/14616734.2018.1517812

Sommerville, R., O'Connor, E. A., \& Asher, L. (2017). Por que os cães brincam? Implicações funcionais e de bem-estar da brincadeira no cão doméstico. Applied Animal Behavior Science, 197, 1-8. https://doi.org/10.1016/j.applanim.2017.09.007

Storengen, L. M, Boge, S. C. K, Strom S. J: Loberg G., \& Lingaas, F. (2014). A descriptive study of 215 dogs diagnosed with separation anxiety. Appl Anim Behav Sci. 159: 82-9. https://doi.org/10.1016/j.applanim.2014.07.006

Wallis, L. J., Szabó, D., Erdélyi - Belle, B., \& Kubinyi, E. (2018). Demographic changes over the life of pet dogs and their impact on health status. Frontiers in Veterinary Sciense. 5 https://doi.org/10.3389/fvets.2018.00200

Wan, Y., Shang, J., Graham, R. S., Baric, F. (2020). Receptor recognition by novel coronavirus from Wuhan: an analysis based on decade-long structural studies of SARS. Journal Virology, https://doi.org/10.1128/jvi.00127-20

Wanser, S. H., \& Udell, M. A. (2019). Does attachment security to a human handler influence the behavior of dogs who engage in animal assisted activities? Applied Animal Behaviour Science. v.210, January 2019, 88-94, https://doi.org/10.1016/j.applanim.2018.09.005.

World Health Organization. Coronavirus disease 2019 (COVID-19) situation report-57. (2020). Geneva, Switzerland: World Health Organization, 2020.

Yamada, R., Kuze-arata, S., Kiyokawa, Y., \& Takeuchi, Y. (2019). Prevalence of 25 canine behavioral problems and relevante factors os each behavior in Japan. Journal of veterinary medical science. 81, 1090 - 1096. https://dx.doi.org/10.1292\%2Fjvms.18-0705 